\title{
Reinke's Crystals in Perivascular and Peritubular Leydig Cells
}

\author{
Viviana Kozina, ${ }^{a}$ Ljerka Banek, ${ }^{a}$ Nikola Knežević, ${ }^{b}$ David Geist, ${ }^{c}$ Lucie Kubinová, ${ }^{d}$ \\ Marin Kosović, ${ }^{\mathrm{e}}$ Christian Rentenberger, ${ }^{\mathrm{c}}$ Andreja Vukasović, ${ }^{\mathrm{a}}$ and Davor Ježek ${ }^{\mathrm{a}, *}$ \\ ${ }^{a}$ University of Zagreb, School of Medicine, Department of Histology and Embryology, Šalata 3, 10000 Zagreb, Croatia \\ 'University of Zagreb, School of Medicine, Clinical Hospital Centre "Zagreb”, Clinic for Urology, Kišpatićeva 12, \\ 10000 Zagreb, Croatia; \\ ${ }^{\mathrm{c}}$ University of Vienna, Faculty of Physics, Boltzmanngasse 5, 1090 Vienna, Austria \\ ${ }^{\mathrm{d}}$ Academy of Sciences of the Czech Republic, Institute of Physiology, Department of Biomathematics, Videňská 1083, \\ 14220 Prague 4, Czech Republic \\ ${ }^{\mathrm{e}}$ University of Zagreb, School of Medicine, Department of Physics, Šalata 3, 10000 Zagreb, Croatia
}

\begin{abstract}
The human testis is composed of seminiferous tubules and interstitium. Within the interstitium, residing Leydig cells can occasionally bear Reinke's crystals. The aim of the current study was to investigate Reinke's crystals in perivascular and peritubular Leydig cells in control and infertile (cryptorchid) testes. For that purpose, bright field, confocal and transmission electron microscopy were applied. The crystal lattice was investigated by Fast Fourier Transformation and the number of crystals determined by stereology. Results of the study indicated a higher number of crystals in perivascular cells (in the both control and cryptorchid group). Moreover, when control and cryptorchid specimens were compared for the presence of the crystal, a higher number of Reinke's crystals was recorded in cryptorchid testes. Thick sections of the crystal were extremely helpful in yielding crystallographic data which confirmed a trigonal crystal structure of the lattice. The exact molecular composition of crystal's microfilaments still remains unknown. (doi: 10.5562/cca1814)
\end{abstract}

Keywords: biocrystals, crystal of Reinke, Leydig cells, transmission electron microscopy, crystallography, stereology

\section{INTRODUCTION}

The parenchyma of the mammalian testis can be divided into two parts: tubular and interstitial compartment. ${ }^{1-3}$ The vast majority of the male sex gonad is occupied by tortuous structures called seminiferous tubules, in which spermatogenesis and production of spermatozoa occur. The interstitial compartment consists of a loose connective tissue rich in blood vessels. However, the most important components of the testis interstitium are Leydig cells. These steroid-producing cells are the main source of testosterone, the male sex hormone. ${ }^{4-7}$ Due to their hormonal activity, Leydig cells create an androgen-rich environment within seminiferous tubules and also exert systemic effect by delivering testosterone to the neighbouring blood vessels. It is well known that target organs for testosterone/androgens released into the blood stream are multitudinous: brain, muscles, bones, skin, kidney, liver, etc. Moreover, testosterone returns via systemic blood stream through the testicular artery and acts on the afore-mentioned testis compartments. ${ }^{8-11}$

Concerning their position within the loose connective tissue of the testis interstitium, Leydig cells can be divided into perivascular and peritubular population of cells. ${ }^{12}$ Perivascular cells are found around blood vessels and distant to seminiferous tubules. Due to their location, it is thought that their major role is secretion of testosterone into the systemic circulation. Peritubular cells, in contrast, are located closely attached to the tubular wall. Sometimes they are even found within the lamina propria, i.e. between the rows of peritubular (myoid) cells. ${ }^{12-15}$ A major part of testosterone from peritubular cells is, very likely, released into the lumen of seminiferous tubules, thus creating a testosterone-rich environment. This process is assisted by Sertoli cells, which secrete androgen binding protein (ABP) that has a high affinity to androgens and accumulates within the fluid of seminiferous tubules. ${ }^{16-17}$

A remarkable feature of the both perivascular and peritubular Leydig cells is an existence of a biocrystal/s

\footnotetext{
$\dagger$ This article belongs to the Special Issue Chemistry of Living Systems devoted to the intersection of chemistry with life.

* Author to whom correspondence should be addressed. (E-mail: davorjezek@yahoo.com)
} 
called crystal of Reinke. ${ }^{18-20}$ Discovered by Reinke in 1896 , these crystals are found only in men with an active spermatogenesis and testosterone production. ${ }^{18,19}$ The crystal itself may be observed in the cytoplasm and/or within the nucleus of Leydig cells. Moreover, it is not present in all cells, but can be occasionally spotted during a routine microscopy of testicular specimens as a normal feature of some Leydig cells. In addition to humans, the crystal can be found in the male gonad of some primates and New Zealand white rabbit. ${ }^{21}$ Comparable structures are noted in Leydig cells of the Australian bush rat. ${ }^{22}$ Reinke's crystals (or Reinke's crystals-like structures) have been described in other cells of the human body, such as hilus cells of the ovary and steroidproducing cells of all three zones of the adrenal cortex..$^{23,24}$

One of the unique characteristics of the testis development is the testicular descent. In humans, the final stages of the descent occur at the end of the pregnancy (month 8-9) and are controlled by insulin-like 3 (INSL3), members of the HOX gene family, testosterone and Müllerian inhibitory substance (MIS). ${ }^{25-28}$ It is thought that these hormones induce a shortening of the gubernaculum testis, a ligament that is attached to the lower pole of each testis. The shortening of the gubernaculum enables the descent of the testis into the scrotal sac, and the development of spermatogenesis at the start of puberty. ${ }^{25-28}$ If the testis has not descended in a regular way, an individual is diagnosed with cryptorchidism. Cryptorchidism is the most frequent disturbance during the development of the male reproductive system in newborns, aborted foetuses, among boys in puberty and in adults. Usually it is one-sided, but it can be bilateral in $10 \%$ to $20 \%$ cases. Moreover, the occurrence of testicular tumours is much higher in cases of untreated cryptorchidism. ${ }^{29-32}$

When dealing with testicular biopsies from men with regular spermatogenesis and cryptorchidism, we observed a higher presence of Reinke's crystals in perivascular and peritubular Leydig cells of latter specimens. There is a lack of data on Reinke's crystals in normal perivascular and peritubular population of Leydig cells. In addition, it is not known if Reinke's crystals and cryptorhidism are somehow connected and which Leydig cell population bears more crystals in the case of this particular disease. Therefore, the aim of our study was to investigate Reinke's crystals in perivascular and peritubular Leydig cells of normal and cryptorchid testis.

\section{EXPERIMENTAL}

\section{Tissue Specimens}

Embedded testicular tissue specimens were retrieved from the tissue archive at Department of Histology and Embryology, School of Medicine, University of Zagreb.
A total number of 230 tissue blocks collected from year 1986 to year 2007 were reviewed. Out of the aforementioned 230 tissue specimens, 20 blocks originating from patients (20-30 years of age) with cryptorchidism were revealed and included into the study. In addition, 6 biopsies from men with obstructive azoospermia and normal histology of the testis were identified and used as a control group.

All patients in the current study were subjected to the open biopsy of the testis. ${ }^{33,34}$ Prior to biopsy, all patients gave their written and informed consent to surgery and biopsy examination. The current study has been approved by an appropriate Ethical Committee. A detailed diagnostic procedure preceded testicular biopsy, including an ultrasound examination of the testes. This diagnostic step provided precise data on the volume of each testis, which were later used for a morphometric (stereological) part of the study. Whenever possible, a bilateral biopsy was performed. Briefly, an incision of $8-10 \mathrm{~mm}$ in length in the $t$. albuginea of the testis has been made. This incision allowed 4-5 testicular lobules to be included into the biopsy. The protruding testicular tissue was dissected using surgical microscissors. Several pieces were taken from different parts of the male gonad. After dissection, all pieces were immediately fixed in Gendre's fluid and buffered 5.5\% glutaraldehyde.

\section{Histological Procedure}

Small pieces of testicular tissue (similar to rice) fixed in Gendre's fluid were dehydrated. For the morphometric (stereological) part of the study, the tissue was allowed to be oriented in a random fashion and embedded in paraffin blocks. Each block was trimmed and oriented (also in a random fashion) for cutting. The blocks were then cut extensively by a rotary microtome (Leitz). Serial sections for a routine bright field microscopy and confocal microscopy (section thickness $=25,10,7$, and $4 \mu \mathrm{m})$ were placed on slides, stained with hematoxylin and eosin and according to the modified Masson's staining procedure. After staining, slides were inspected by a binocular microscope Ecllipse 200 (Nikon) in order to identify Reinke's crystals.

Tissue fixed in glutaraldehyde was rinsed several times in $0.05 \mathrm{M}$ phosphate buffer $(\mathrm{pH}=7.1-7.4$, $800 \mathrm{mOsm}$ ), postfixed with $1 \% \mathrm{OSO}_{4}$ and dehydrated. After a routine histological procedure, the testicular tissue was embedded in Durcopan (Agar). Semi-thin sections (section thickness $=0.9 \mu \mathrm{m}$ ) were obtained with a Reichert ultramicrotome and stained with $1 \%$ toluidine blue. Ultra-thin sections were made (section thickness $=70-300 \mathrm{~nm}$ ), contrasted with lead citrate and uranyl acetate and examined by a transmission electron microscope Zeiss 902A (Centre for Electron Microscopy, Medical School University of Zagreb). For additional studies, a transmission electron microscope 


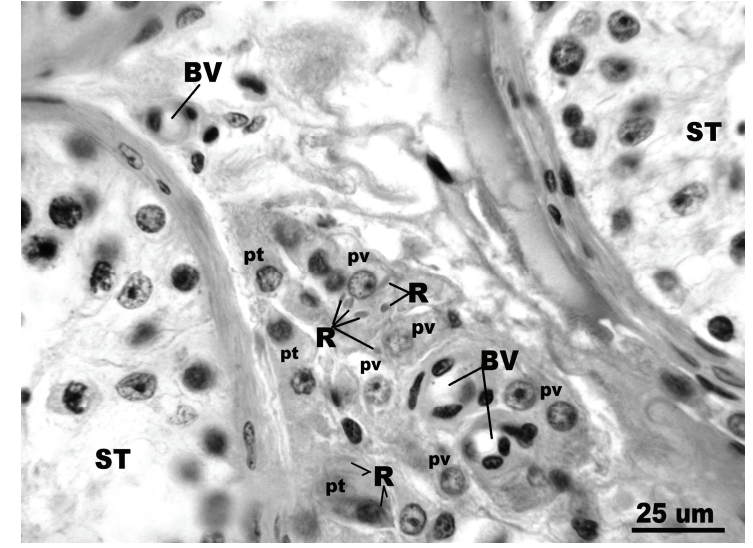

(a)

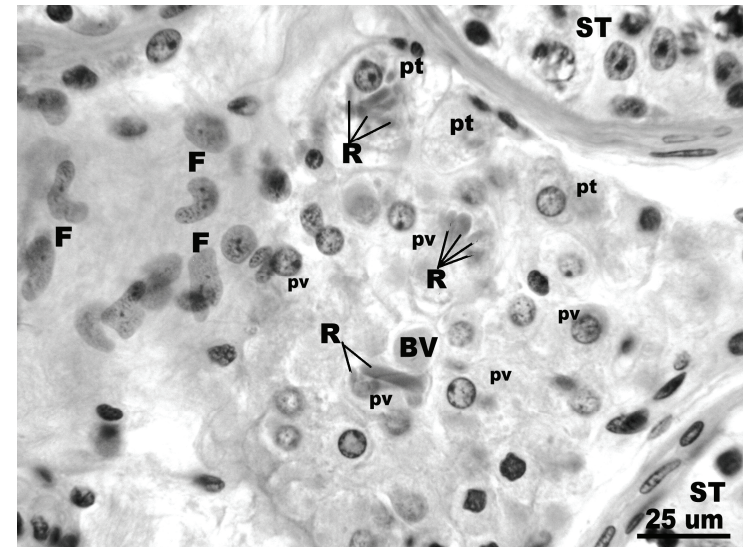

(b)

Figure 1. Reinke's crystals in perivascular and peritubular Leydig cells visualized by bright field microscopy. (a) In the control specimen, perivascular Leydig cells (pv) were found in the vicinity of blood vessels (BV) and contained a moderate number of Reinke's crystals (R). Peritubular Leydig cells (pt) were localized in the close proximity of seminiferous tubules (ST) and their cytoplasm demonstrated lesser presence of the crystal. (b) Part of the interstitial tissue of the cryptorchid testis. Between seminiferous tubules, in addition to perivascular and peritubular Leydig cells, a significant number of fibroblasts (F) were noted. Abundant presence of Reinke's crystal in both groups of Leydig cells could be recorded. (Hematoxylin eosin stain, scale bar $=25 \mu \mathrm{m}$ )

Philips CM 200 (Faculty of Physics, University of Vienna) was employed.

\section{Confocal Microscopy}

Images of test specimens were acquired by a Leica SP2 AOSB confocal laser scanning microscope (CLSM) (Academy of Sciences of the Czech Republic, Institute of Physiology, Department of Biomathematics, Prague) using an excitation wavelength of $488 \mathrm{~nm}$ yielded by an Ar laser $(20 \mathrm{~mW})$. The images (with voxel dimensions of $37 \mathrm{~nm} \times 37 \mathrm{~nm} \times 81 \mathrm{~nm}$ ) were acquired by use of a HCX PL APO CS 100x oil immersion objective (N.A. $=1.40$ ) using the emission wavelength range from $512 \mathrm{~nm}$ to $583 \mathrm{~nm}$.

\section{Crystallographic Analysis}

For the crystallographic analysis of Reinke's crystals, a Philips CM200 transmission electron microscope (TEM) (University of Vienna, Faculty of Physics) operating at acceleration voltages from $80 \mathrm{kV}$ to $150 \mathrm{kV}$ was used. The instrument was equipped with a rotational tilt sample holder, allowing an inclination of the sample of $60^{\circ}$ in any direction. To analyze the crystal structure, images were taken at a lattice resolution and processed by a Fast Fourier Transformation (FFT) to get the average lattice information of the whole image. This is possible since the FFT fulfils the following two conditions: (1) Spots in the FFT-processed image lie perpendicular to the corresponding lattice planes in the real image. This means that the angular correlations of the lattice planes of the real image are conserved in the FFT. (2) Distances $d_{\text {FFT }}$ from the centre to the spots in the FFTprocessed image are in a reciprocal relationship to the distances $d_{\text {real }}$ of adjacent crystal lattice planes (lattice parameter) in the real image

$$
d_{\text {real }}=\frac{1}{d_{\mathrm{FFT}}}
$$

\section{Morphometric (Stereological) Analysis}

Sixty serial paraffin sections were made per block, mounted on 10 slides (each slide bearing 6 sections) and stained as mentioned previously. A test point grid $^{35}$ with 42 test points was inserted into the eyepiece of two binocular microscopes (Carl Zeiss, Jena). The first and the sixth slide were used for a morphometric measurement, applying a physical disector principle. ${ }^{36-38} \mathrm{Sec}-$ tions were observed at a magnification of X1000 (without re-focusing) where the test surface area (At) was $0.0144 \mathrm{~mm}^{2}$ for each analyzed microscopic field. The distance between the analyzed sections was determined by section thickness $(d=4 \mu \mathrm{m})$. For each biopsy, 300 microscopic fields were assessed. The number of perivascular and peritubular Leydig cells as well as Reinke's crystals within the unit volume $\left(\mathrm{mm}^{3}\right)$ of the testis tissue (numerical density or relative value - $N \mathrm{v}$ ) as well as per the whole organ (absolute number or value $-N$ ) were determined. Only crystals within the cytoplasm of perivascular and peritubular Leydig cells were considered. The crystals localized in the nucleus of Leydig cells were not assessed, since their number could not be unquestionably determined at the level of bright field microscopy. In order to calculate the above-mentioned relative variable, appropriate formulae for numerical density have been applied. ${ }^{35-39}$ The total number of crystals was determined by multiplying the testis volume (determined by the ultrasound examination) and numerical density. ${ }^{35}$ 


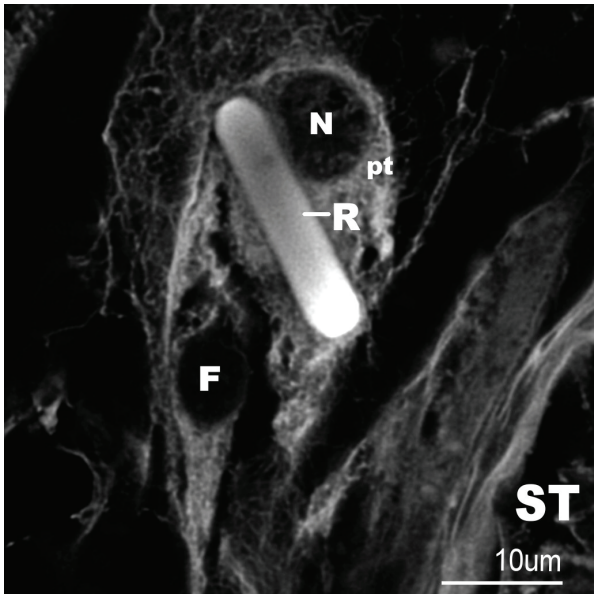

(a)

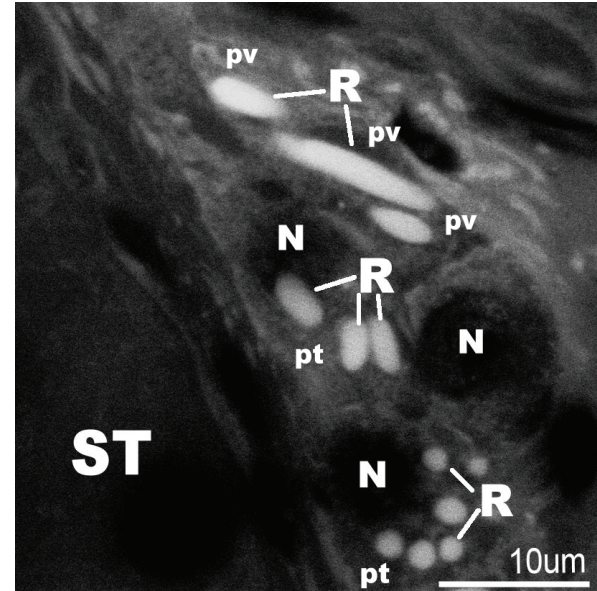

(b)

Figure 2. Confocal images of Reinke's crystals in the control (a) and cryptorchid (b) specimens. (a) A large crystal (R) in the peritubular Leydig cell (pt) of the control biopsy, cut longitudinally ( $\mathrm{N}$ - cell nucleus; F - fibroblast; ST - seminiferous tubule). (b) Numerous crystals found within the cytoplasm of both perivascular (pv) and peritubular (pt) Leydig cells of cryptorchid testis cut in various planes. (Hematoxylin eosin stain, scale bar $=10 \mu \mathrm{m}$ )

\section{Statistical Analysis}

Data were statistically analyzed using Statistica 8.0 software developed by StatSoft ${ }^{\circledR}$. The statistically significant difference between the control and cryptorchid group of patients was determined using non-paired Student's t-test. $P<0.01$ indicated a statistically significant difference between the two groups. Graphs represent mean values and standard errors of means.

\section{RESULTS}

\section{Bright Field Microscopy}

Control biopsies showed a regular morphology of seminiferous tubules and a normal architecture of interstitial tissue. Within the interstitial tissue, two groups of Leydig cells could be clearly distinguished ${ }^{12}$ : perivascular Leydig cells, localized in the vicinity of blood vessels and peritubular Leydig cells situated in the close proximity of seminiferous tubules (Figures $1 \mathrm{a}$ and $1 \mathrm{~b}$ ). Perivascular group of Leydig cells had a regular, round or oval nucleus with occasionally well-visible nucleolus. Their cytoplasm was abundant, ovoid or polygonal, equally distributed around the nucleus. Perivascular Leydig cells contained a moderate number of Reinke's crystals (Figure 1a). Peritubular Leydig cells were frequently found close to the lamina propria of seminiferous tubules. Some cells were much similar in shape to the above-mentioned perivascular group. However, a number of peritubular cells had more elongated nucleus and cytoplasm, thus following the curvature of seminiferous tubules wall. Although Reinke's crystals could be well identified in these cells, it seemed that their number was lower than that present in the perivascular cells (Figures 1a and 1b). In the infertile (cryptorchid) group of patients, a variety of degenerative changes of seminiferous tubules could be found. In the interstitial compartment, again, two groups of Leydig cells might be clearly recognized, as described above. Frequently, a hypertrophy and hyperplasia of Leydig cells could be seen, resulting in abundant presence of these cells in the interstitial compartment of cryptorchid specimens (Figure 1b). In some cases, a loose connective tissue was also augmented, with a lot of fibroblasts situated between the neighbouring seminiferous tubules (Figure 1b). Cryptorchid specimens contained numerous Reinke's crystals. Plentiful presence of crystals could be recorded both in the perivascular as well as in the peritubular population of Leydig cells (Figure 1b). However, the majority of the crystals were seen in the perivascular Leydig cells.

\section{Confocal Microscopy}

Much more precise images of the crystal could be observed using confocal microscopy. When stained with eosin, the crystals acquire fluorescence properties and, therefore, could be easily detected. In the control and cryptorchid specimens the crystals were cut in various directions and planes; thus, longitudinal, cross and oblique sections of the crystal could be observed (Figures $2 \mathrm{a}$ and $2 b$ ). Longitudinally sectioned crystals were from time to time of huge size reaching approx. $10 \mu \mathrm{m}$ or even more (Figure 2a). The rod shaped crystals dominated, and could be observed in the both perivascular and peritubular Leydig cells (Figures 2a and 2b). When cryptorchid specimens were concerned, Reinke's crystals were more frequently encountered in Leydig cells when compared to controls. In cryptorchid group, some Leydig cells contained more than five crystals cut in various directions (Figure 2b). Some crystals were found in the cytoplasm, distant to the nucleus of the cell; however, 


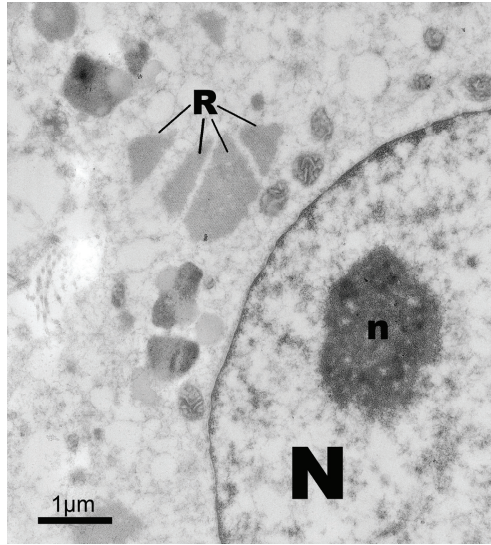

(a)

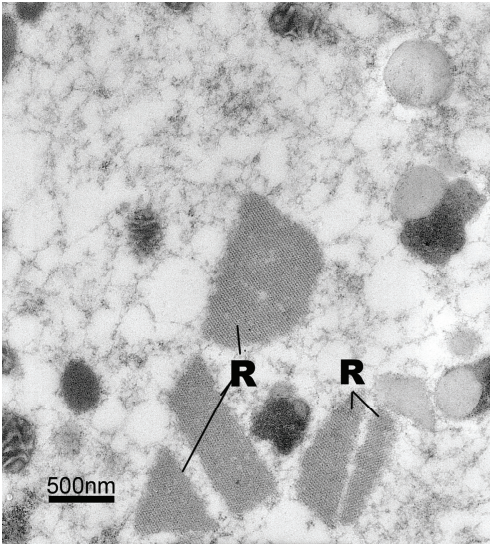

(b)

Figure 3. Transmission electron microscopy of a perivascular Leydig cell (cryptorchid group of patients). (a) In the perinuclear region, several crystals $(\mathrm{R})$ were present ( $\mathrm{N}$ - nucleus; $\mathrm{n}$ - nucleolus). (b) Detail of the previous figure. Crystals had various size and shape, due to the section plane and their phase of "maturation". Within the individual crystal, small microfilaments could be seen. (Ultrathin section, scale bar $=1 \mu \mathrm{m} / \mathrm{a} /$ and $500 \mathrm{~nm} / \mathrm{b} /$ )
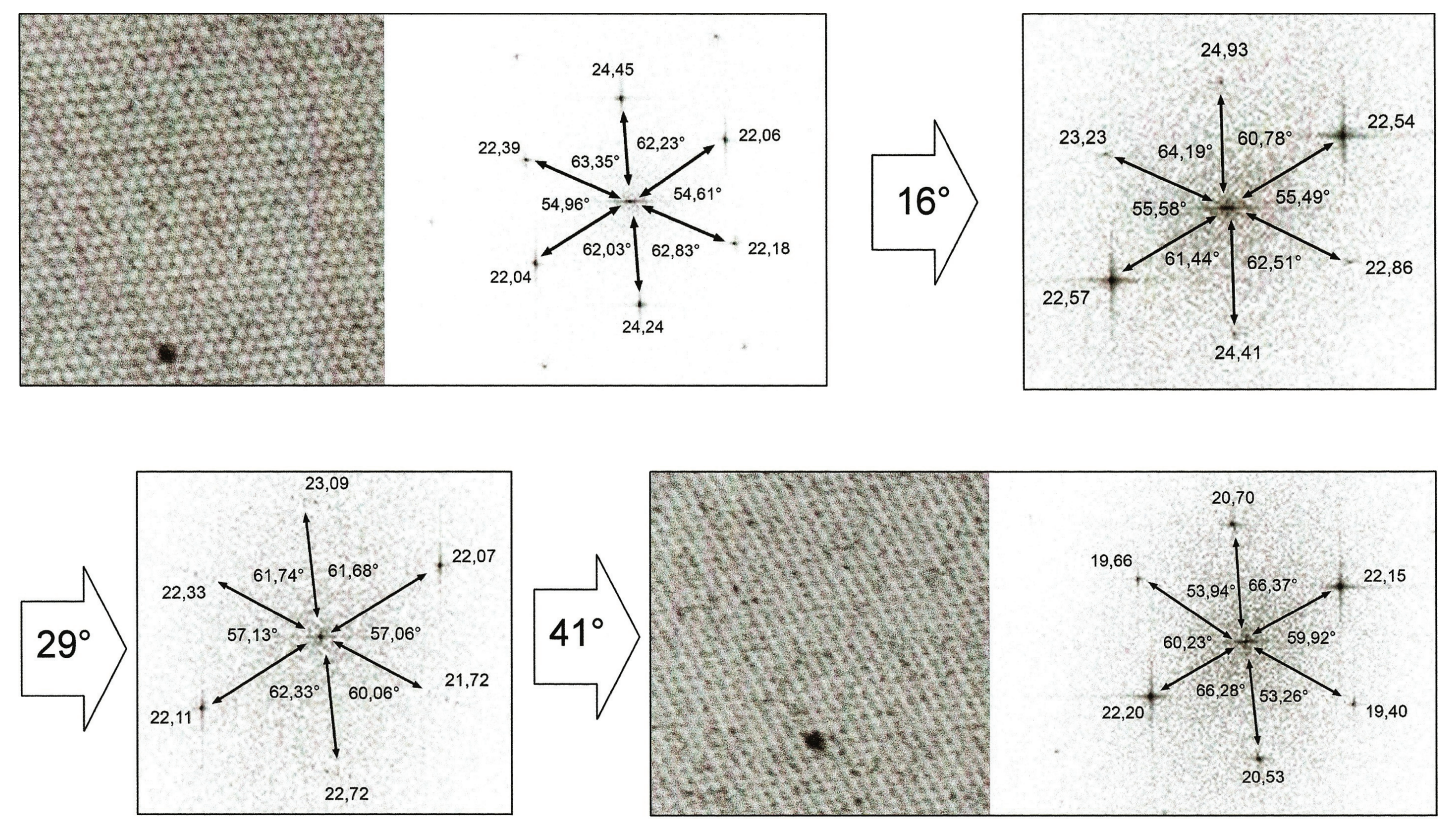

Figure 4. Fast Fourier Transformation (FFT) on the thick sections (up to $300 \mathrm{~nm}$ ) of the crystal, tilted at various degrees. The crystal lattice demonstrated a remarkable regular composition, and the data obtained supported a trigonal crystal structure for Reinke's crystals.

very often, crystals were recorded in the perinuclear area or in the contact with the nucleus (Figures $2 \mathrm{a}$ and $2 \mathrm{~b}$ ).

\section{Transmission Electron Microscopy and Crystallograph- ic Analysis}

Transmission electron microscopy demonstrated a variety of crystal shapes and appearances. Although the "mature" crystal had a hexagonal structure, a lot of crystals presented more "immature" form, bearing three, four or five angles. Frequently, two or more crystals have been found running in a parallel fashion, facing each other (Figures $3 \mathrm{a}$ and $3 \mathrm{~b}$ ). They were composed of microfilaments $(5-10 \mathrm{~nm}$ in size), without the unit membrane (Figure 3b). No significant difference in the ultrastructural architecture of the crystal could be observed between perivascular and peritubular Leydig cells of both control and cryptorchid specimens.

The crystal lattice was of a honeycomb pattern, showing small hexagonal filaments closely packed to each other (Figure 4). It was established that routine ultra-thin sections (normally used for biomedical research) of $70 \mathrm{~nm}$ thickness yield rather vague data when a Fast Fourier Transformation (FFT) is applied. More specific, some lattice parameters varied up to $57 \%$, which was due to properties of the biocrystal and limitations of section thickness. Sample thicknesses of more 
Table 1. Testis volume in control and infertile (cryptorchid) group of patients

\begin{tabular}{cccc}
\hline$V / \mathrm{mm}^{3}$ & CONTROL & CRYPTORCHID & $P$ \\
\hline$s$ & 1201.58 & 2965.87 & $<0.001$ \\
$\bar{X}$ & 21063.33 & 11333.00 & \\
$\mathrm{SE}$ & 490.54 & 663.19 & 0.06 \\
$\mathrm{RSE}$ & 0.02 & 0.06 & \\
\hline
\end{tabular}

Table 2. Number of perivascular and peritubular Leydig cells per the whole organ (absolute values, $N_{\mathrm{L}}$ )

\begin{tabular}{cccc}
\hline$N_{\mathrm{L}}$ & $\begin{array}{c}\text { Number of PERIVASCULAR } \\
\text { Leydig cells } / \times 10^{6}\end{array}$ & $\begin{array}{c}\text { Number of PERITUBULAR } \\
\text { Leydig cells } / \times 10^{6}\end{array}$ & $P$ \\
cryptorchid / control & $263.53 / 245.84$ & $113.39 / 100.43$ & \\
$S$ & $596.93 / 642.9$ & $349.18 / 384.39$ & $>0.05$ \\
$\bar{X}$ & $58.93 / 100.36$ & $25.35 / 41$ & \\
$\mathrm{SE}$ & $0.1 / 0.16$ & $0.07 / 0.11$ & \\
$\mathrm{RSE}$ & &
\end{tabular}

than $300 \mathrm{~nm}$, on the other hand, worsen the transmission of the electrons, since acceleration voltages of more than $150 \mathrm{kV}$, which would allow for thicker specimens, cause damage in the sample. Therefore, samples with different thicknesses ranging from $70 \mathrm{~nm}$ to $300 \mathrm{~nm}$ were used for the crystallographic part of the study. FFT clearly demonstrated an extremely regular crystalline lattice (Figure 4). Within the experimental uncertainties caused by the above-mentioned effects, the results of the crystallographic TEM analysis are in accordance with a previous work ${ }^{20}$ that proposes a trigonal crystal structure for Reinke's crystals.

\section{Testis Volume and Stereological Analysis}

The testis volume (determined by ultrasound) was significantly decreased in the group of patients diagnosed with cryptorchidism. The average volume of control testes was approx. $21 \mathrm{~cm}^{3}$ whereas the same parameter in the cryptorchid group was roughly $50 \%$ reduced
$(P<0.001)($ Table 1$)$.

Morphometric (stereological) analysis showed that the perivascular Leydig cell population was larger both in control and cryptorchid specimens. The number of peritubular cells was lower in the both investigated groups (when compared to perivascular Leydig cells). Thus, the observed ratio between perivascular and peritubular cells in control and infertile group of patients was approximately $1.7: 1$. There was no significant difference between the presence of Leydig cells populations and their ratios between the control and cryptorchid group $(P>0.05)$ (Table 2$)$.

Stereological analysis also pointed out that there is a slight difference in the number of Reinke's crystals between perivascular and peritubular Leydig cells. Although not statistically significant, the morphometric analysis showed that perivascular Leydig cells had larger number of crystals in the control as well as in the cryptorchid group of patients (Figures $5 \mathrm{a}$ and $5 \mathrm{~b}$ ). When

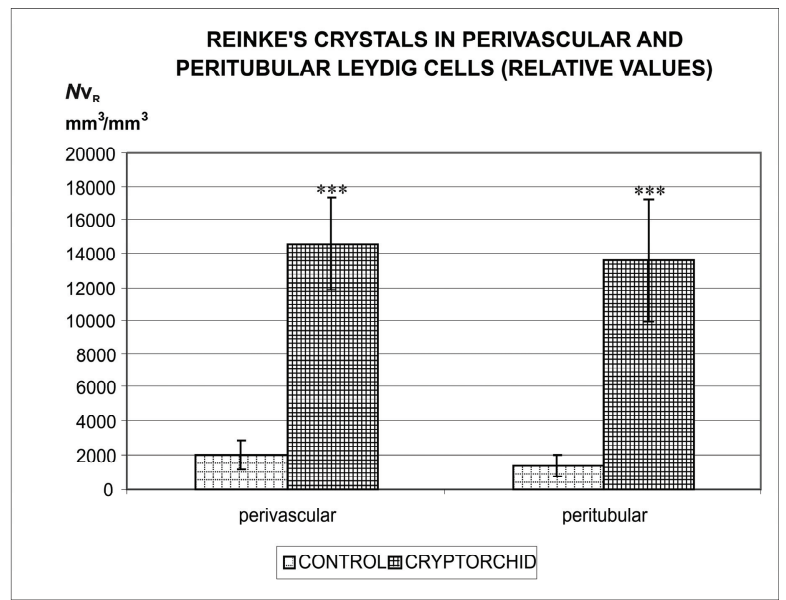

(a)

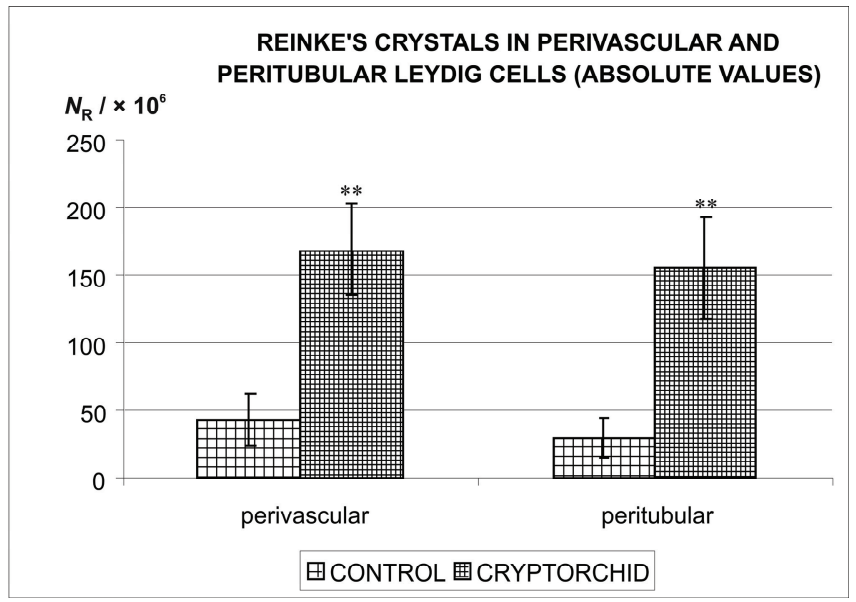

(b)

Figure 5. Number of Reinke's crystal in peritubular and perivascular Leydig cells in $\mathrm{mm}^{3}$ of the male gonad (relative values or numerical density, $N_{\mathrm{R}}$ ) (a) and in the whole organ (absolute values, $N_{\mathrm{R}}$ ). (b) The data established (in the both investigated groups of patients) that the number of crystals in perivascular Leydig cells was higher than that measured in peritubular cells. When compared to controls, the number of Reinke's crystals in perivascular and peritubular Leydig cells was statistically significantly increased in cryptorchid specimens $(* * P<0.01 ; * * P<0.001)$. 
compared to controls, cryptorchid specimens contained significantly more crystals, both in the perivascular as well as in peritubular Leydig cells. This difference is more profound in the perivascular population of Leydig cells $(P<0.001)$ (Figures 5a and 5b). However, the statistically significant difference in the presence of the crystal could be disclosed when peritubular Leydig cells of the control and cryptorchid group were concerned $(P<0.01)$ (Figures 5a and 5b).

\section{DISCUSSION}

It is generally accepted that Leydig cells originate from mesenchymal cells of the genital ridge or primitive gonad. Recent data focus on blood vessels precursors. ${ }^{40-43}$ Foetal Leydig cells are potent source of testosterone that induces the development of other parts of the male reproductive system. The activity of these cells is under the strong influence of the foetal pituitary gland. Despite their resemblance to the adult type of Leydig cells, foetal ones do not have Reinke's crystals. ${ }^{19}$ Moreover, a potential role in the development of Leydig cells could play cells of the neural crest, since Leydig cells (or at least their distinctive subpopulation) clearly express many neuronal/glial markers. Thus, Leydig cells, in addition to the well established steroid-producing activity, seem to be a part of a diffuse neuroendocrine system (DNS). ${ }^{44-46}$

The process of spermatogenesis is highly dependent upon androgens and small quantities of estrogens. ${ }^{47-50}$ It can be speculated that the major supplier of testosterone for seminiferous tubules are, in fact, peritubular Leydig cells. In humans, the lamina propria of seminiferous tubules is composed of 5-7 layers of peritubular (myoid) cells. These cells have properties of smooth muscle cells and fibroblasts. Peritubular Leydig cells are located in the close proximity of the lamina propria. Moreover, in some cases, peritubular cells could be found between rows of myoid cells. ${ }^{14}$ Therefore, one can speculate that these cells develop in a parallel fashion with cells of the lamina propria from the common precursor. The development of peritubular Leydig cells could be stimulated by a number of paracrine factors of sex cords, future seminiferous tubules. On their part, peritubular cells act locally on the seminiferous epithelium by a direct delivery of huge amounts of testosterone.

In contrast to peritubular cells, perivascular Leydig cells, by distributing testosterone into the blood, have a systemic effect. A number of important organs are under the influence of blood testosterone and perivascular cells: brain, pituitary gland, skin, bones, muscles, liver, kidney and many other organs and tissues. Thus, from "evolutionary standpoint" one can speculate that peritubular Leydig cells developed in response to the need for androgen-rich local microenvironment (seminiferous tubules) whereas perivascular Leydig cells arise as consequence of a need for a systemic effect of androgens. Perivascular cells, in addition, thus control the hypothalamus-hypophysis-testis axis and activity of the two testis compartments. ${ }^{1-3}$

Both perivascular and peritubular Leydig cells have Reinke's crystals. Some investigators speculate that this crystal is a by-product of steroidogenesis and the production of testosterone. ${ }^{19,52,53}$ Indeed, crystals could arise from products of Leydig cells metabolism that progressively accumulate within the cytoplasm of these cells. The definitive, rod-shaped hexagonal crystal, is, very likely, preceded by some smaller and more irregular forms. Our confocal images and transmission electron microscopy data are in favour of the abovementioned concept of crystal "maturation". Under the transmission electron microscope, a lot of "immature" crystal forms with 4-5 angles could be seen. The crystals often oppose to each other and are divided by small gaps. Their arrangement seems to support building of a larger crystal from smaller, immature forms. ${ }^{39}$

In specimens originating from control biopsies we were able to establish a certain difference in number of Reinke's crystals in perivascular and peritubular Leydig cells. Although not statistically significant, our stereological data indicated a lower number of crystals in peritubular cells. This is due to the fact that the perivascular cell population is more abundant. However, another reason for the above-mentioned observation could be the shape of cells and their cellular organization. Peritubular Leydig cells much resemble their mesenchymal precursors and are very often elongated, even spindle-shaped and follow the convolution of the wall of seminiferous tubule. Thus, the shape of this cell type does not favour the formation of large crystals (visible by bright field microscopy). In contrast, perivascular cells are more ovoid or round (epithelial-like) and provide necessary "space" for the development of large and well-visible crystals. Another reason could be in a different metabolism and testosterone dynamic. If Reinke's crystals and steroidogenesis (testosterone production) are really connected, one can speculate that peritubular cells do not accumulate many steroid metabolites and testosterone in their cytoplasm. On the contrary, testosterone is immediately distributed to seminiferous tubule in order to maintain spermatogenesis. Perivascular Leydig cells could deposit steroid products including testosterone for a longer period, thus inducing the formation of more crystals with different sizes.

Our stereological data pointed out a statistically significant increase in the number of Reinke's crystals in cryptorchid specimens when compared to controls. Moreover, the number of crystals in perivascular Leydig cells of cryptorchid specimens was higher than that 
recorded in peritubular Leydig cells (originating from the same infertile group of patients). Since we investigated patients with a long history of cryptorchidism, where testes were malpositioned in the abdominal cavity for years or had a high scrotal position (18-21 years) before orchidopexy, one could speculate about the influence of a temperature on the formation of the Reinke's crystal. It has been well established that scrotal sac maintains a temperature even $3-5^{\circ} \mathrm{C}$ lower than that within the abdominal cavity or the human body in general. ${ }^{25-28}$ It can be postulated that a prolonged exposure of the testis to higher temperature stimulated enzymes involved in the accumulation of microfilaments and formation of the crystal. Control group of testes were harboured within the scrotal sac and, therefore, exposed to the normal (lower) temperature which could slow down the activity of enzymes engaged in the crystal formation. What enzymes are at stake is, up to now, not known.

Using Fast Fourier Transformation (FFT), we were able to document a neat organisation of the crystal lattice. Sections up to $300 \mathrm{~m}$ of thickness were helpful in the analysis of the lattice. Using relatively thick sections of the crystal, much more data were collected by FFT. The results of the crystallographic TEM analysis were in accordance with previous work ${ }^{20}$ that proposed a trigonal crystal structure for Reinke's crystals. Although it is generally thought that the crystal is of a protein nature, its exact molecular composition is still not known. ${ }^{18-20}$ Recent immunohistochemical data indicate the presence of cytoskeletal protein nestin. ${ }^{53}$ Therefore, one can speculate that the crystal is a deposit of cytoskeletal elements. If these are linked to steroidogenesis and testosterone production is obscure.

\section{CONCLUSION}

Reinke's crystals are normal constituents of Leydig cells. These steroid-producing cells are responsible for the production of the male sex hormone, testosterone. According to their position within the interstitium of the testis, Leydig cells can be divided into the perivascular (located around blood vessels) and peritubular (situated in the close proximity of seminiferous tubules). The aim of the current study was to investigate Reinke's crystals in perivascular and peritubular Leydig cells in control and cryptorchid specimens. For that purpose, bright field, confocal and transmission electron microscopy were applied. In addition, the crystal lattice was investigated by Fast Fourier Transformation and the number of crystals in control and cryptorchid specimens was determined by morphometry (stereology). The results of the study indicated a higher number of crystals in perivascular cells in the both control and cryptorchid groups of patients. Moreover, when control and cryptorchid specimens were checked for the presence of crystal, the stereological analysis clearly pointed out the statistically higher number of Reinke's crystal in cryptorchid testes. Thick sections of the crystal were extremely helpful in yielding the crystallographic data. Transmission electron microscopy data confirmed the previously described architecture of the crystal and a trigonal crystal structure of the lattice. Despite detailed analysis of the lattice, the molecular composition of crystal's microfilaments remains unknown.

Acknowledgments. The study was supported by: a) bilateral Croatian-Austrian project entitled "Reinke's crystals in healthy and infertile men", funded by Ministries of Science, Education and Sport of Republic of Croatia and Republic of Austria; b) grant No. 108-1080399-0383, Ministry of Science, Education and Sport, Republic of Croatia; c) the Academy of Sciences of the Czech Republic (Institutional Research Concept No. AV0Z50110509); d) Ministry of Education, Youth and Sports of the Czech Republic (project No. LC06063).

\section{REFERENCES}

1. D.D. Mruk, and C.Y. Cheng, Philos. Trans. R .Soc. Lond. B. Biol. Sci. 365 (2010)1621-1635.

2. H.H. Yan, D.D. Mruk, W.M. Lee, and C.Y. Cheng, Adv. Exp. Med. Biol. 636 (2008) 234-254.

3. Y. Hodgson, D.M. Robertson, and D.M. de Kretser, Int. Rev. Physiol. 27 (1983) 275-327.

4. H.M. Scott, J.I. Mason, and R.M. Sharpe, Endocr. Rev. 30 (2009) 883-925.

5. H. Chen, R.S. Ge, and B.R. Zirkin, Mol. Cell Endocrinol. 306 (2009) 9-16.

6. V.S. Wilson, C.R. Blystone, A.K. Hotchkiss, C.V. Rider, and L.E. Gray Jr., Int. J. Androl. 31 (2008) 178-187.

7. F. Lombardo, P. Sgrò, P. Salacone, B. Gilio, L. Gandini, F. Dondero, E.A. Jannini, and A. Lenzi, J. Endocrinol. Invest. 28 (2005) 51-55.

8. M. Huleihel, and E. Lunenfeld, Asian J. Androl. 6 (2004) 259268.

9. S.Carreau, Folia Histochem. Cytobiol. 34 (1996) 111-119.

10. R.M. Sharpe, S. Maddocks, and J.B. Kerr, Am. J. Anat. 188 (1990) 3-20.

11. J.M. Saez, M.H. Perrard-Sapori, P.G. Chatelain, E. Tabone, and M.A. Rivarola, J. Steroid Biochem. 27(1987) 317-329.

12. R. Paniagua, M.C. Rodríguez, M. Nistal, B. Fraile, J.Regadera, and P. Amat, Anat. Embryol. (Berl). 178 (1988) 423-427.

13. S. Ergün, J. Stingl, and A.F. Holstein, Andrologia 26 (1994) 255-262.

14. C. Schulze, and A.F. Holstein, Andrologia 10 (1978) 444-452.

15. R. Middendorff, M.S. Davidoff, S. Behrends, M. Mewe, A. Miethens, and D. Müller, Andrologia 32 (2000) 55-59.

16. G.R. Dohle, M. Smit, and R.F. Weber, World J. Urol. 21(2003) 341-345.

17. A.G. Davies, Arch. Androl. 7 (1981) 97-108.

18. F. Reinke, Arch. Mikr. Anat. 47 (1896) 34-44.

19. C. Schulze, Adv. Anat. Embryol. Cell Biol. 88 (1984) 1-104.

20. T. Nagano, and I. Ohtsuki, J. Cell Biol. 51 (1971)148-161.

21. F. Marino, G. Ferrara, G. Rapisarda, and V. Galofaro, Reprod. Domest. Anim. 38 (2003) 421-422.

22. J.B. Kerr, D.C. Abbenhuys, and D.C. Irby, Cell Tissue Res. 245 (1986) 91-100. 
23. M.C. Magalhàes, J. Cell Biol. 55 (1972) 126-133.

24. M .Paraskevas, and R.E .Scully, Int. J. Gynecol. Pathol. 8 (1989) 299-310.

25. F. Massart, and G.Saggese, Sex Dev. 4 (2010) 326-335.

26. J.M. Hutson, A. Balic, T. Nation, and B. Southwell, Semin. Pediatr. Surg. 19 (2010) 215-224.

27. R.A. Ashley, J.S. Barthold, and T.F. Kolon, Urol. Clin. North Am. 37 (2010) 183-193.

28. N.O. Hadziselimovic, Ch. de Geyter, P. Demougin, E.J. Oakeley, and F. Hadziselimovic, Urol. Int. 84 (2010) 353-361.

29. J. Toppari, H.E. Virtanen, K.M. Main, and N.E. Skakkebaek, Res. A. Clin. Mol. Teratol. 88 (2010) 910-919.

30. T.H. Schnack, G. Poulsen, C. Myrup, J. Wohlfahrt, and M. Melbye, J. Natl. Cancer Inst. 102 (2010) 187-192.

31. S. La Vignera, A.E. Calogero, R. Condorelli, A. Marziani, M.A. Cannizzaro, F. Lanzafame, and E. Vicari, Eur. Rev. Med. Pharmacol. Sci. 13 (2009) 351-356.

32. M.J. Mathers, H. Sperling, H. Rübben, and S. Roth, Dtsch. Arztebl. Int. 106 (2009) 527-532.

33. A.F. Holstein, B. Schütte, H. Becker, and M. Hartmann, Int. J Androl. 10 (1987)1-18.

34. W. Schulze, M.S. Davidoff, A.F. Holstein, and C. Schirren, Andrologia 19 (1987) 419-422.

35. E.R. Weibel, Bull. Eur. Physiopathol. Respir. 15 (1979) 999-1013.

36. J.F. Bertram, Int. Rev. Cytol. 161 (1995):111-172.

37. R.P. Bolender, D.M. Hyde, and R.T. Dehoff, Am. J. Physiol. 265 (1993) L521-548.

38. H.J. Gundersen, R.W. Boyce, J.R. Nyengaard, and A.Odgaard, Bone 14 (1993) 217-222.

39. Kozina V.,Geist D., Kubinová L., Bilić E., Karnthaler H.P., Waitz T., Janáček J., Chernyavskiy O., Krhen I., Ježek D., Histochem. Cell. Biol. 135 (2011) 215-228.
40. E.N. Wainwright, and D. Wilhelm, Curr. Top. Dev. Biol. 90 (2010) 231-262.

41. M.S. Davidoff, R. Middendorff, D. Müller, and A.F. Holstein, Adv. Anat. Embryol. Cell Biol. 205 (2009) 1-107.

42. M.S. Davidoff, R. Middendorff, G. Enikolopov, D. Riethmacher, A.F. Holstein, and D. Müller, J. Cell Biol. 167 (2004) 935-944.

43. K. Jeays-Ward, C. Hoyle, J. Brennan, M. Dandonneau, G. Alldus, B. Capel, and A. Swain, Development 130 (2003) 3663 3670 .

44. M.S. Davidoff, R. Middendorff, E. Köfüncü, D. Müller, D. Jezek, and A.F. Holstein, Acta Histochem. 104 (2002) 39-49.

45. M.S. Davidoff, R. Middendorff, Y. Koeva, W. Pusch, D. Jezek, and D. Müller, Ital. J. Anat. Embryol. 106 (2001) 173-180.

46. M.S. Davidoff, R. Middendorff, W. Pusch, D. Müller, S. Wichers, and A.F. Holstein, Histochem. Cell Biol. 111 (1999) 173-187.

47. S. Carreau, R.A. Hess, Philos. Trans. R. Soc. Lond. B. Biol. Sci. 365 (2010) 1517-1535.

48. G. La Sala, D. Farini, and M. De Felici, Int. J. Dev. Biol. 54 (2010) 717-722.

49. J.E. Cavaco, S.S. Laurentino, A. Barros, M. Sousa, and S. Socorro, Syst. Biol. Reprod. Med. 55 (2009) 137-144.

50. S. Carreau, D. Silandre, C. Bois, H. Bouraima, I. GaleraudDenis, and C. Delalande, Folia Histochem. Cytobiol. 45 (2007) S5-10.

51. R. Paniagua, P. Amat, M. Nistal, and A. Martin, J. Anat. 146 (1986) 173-183.

52. R. Paniagua, M. Nistal, and M.P. Bravo, Hum. Pathol. 15 (1984) 181-190.

53. M.V. Lobo, M.I. Arenas, F.J. Alonso, G. Gomez, E. Bazán, C.L. Paíno, E. Fernández, B. Fraile, R. Paniagua, A. Moyano, and E. Caso, Cell Tissue Res. 316 (2004) 369-376. 